\title{
Technological Adjuncts to Increase Adherence to Therapy:
}

\section{A Review}

\author{
Bonnie A. Clough ${ }^{a *}$ \\ Leanne M. Casey ${ }^{\mathrm{a}}$ \\ ${ }^{a}$ Griffith Health Institute, Griffith University, Brisbane, \\ Queensland, Australia
}

*Correspondence should be addressed to Bonnie A. Clough, School of Psychology, Griffith University, Mt Gravatt Campus, Brisbane, QLD 4111, Australia (email: b.clough@griffith.edu.au). Telephone: +61 7 37353348. Fax: +61 737353388 


\begin{abstract}
This paper identified and reviewed technological adjuncts to increase client adherence to therapy. Three areas of adherence were identified, namely treatment dropout and nonattendance, engagement during and between therapy sessions, and aftercare. Database searches were conducted in each of these areas to identify relevant studies published between the years of 1990-2010. Adjuncts designed to replace or reduce direct therapist contact, change the medium of communication between the client and therapist, or alter the content or style of the therapy were not included in this review. Adjuncts were reviewed in light of theories of adherence, including Self Determination Theory, the Transtheoretical Model, and the Theory of Planned Behaviour. Adjuncts reviewed included appointment reminders, exercises and monitoring delivered by mobile phone, and exercises and data collection delivered by computer. Limitations and directions for future research were addressed and discussed.
\end{abstract}

Keywords: technology, adherence, compliance, dropout, reminders, engagement, homework, aftercare. 


\section{Technological Adjuncts to Increase Adherence to Therapy: A Review}

\section{Adherence to the Therapeutic Process}

Adherence in psychological practice may be thought of as the extent to which a person's behaviours follow the advice given by healthcare professionals (Friedman \& Litt, 1987; McDonald, Garg, \& Haynes, 2002; Nose, Barbui, Gray, \& Tansella, 2003). These behaviours may include entering a treatment programme, maintaining and completing a treatment programme, keeping aftercare appointments, and taking prescribed medication (Chen, A., 1991; Nose et al., 2003). Adherence can also include engaging in therapy sessions, openness and personal disclosure, and cooperation (Krause, 1967).

Problems with adherence can often lead to poorer treatment outcomes at many stages in the therapeutic process (Haynes, McDonald, \& Garg, 2002). Although compliance with clinical medications has been estimated at approximately 50\%, adherence with behavioural regimes is often even lower (Haynes et al., 2002). Patient dropout, poor engagement, and homework compliance are all adherence issues that often reduce the success and effectiveness of treatment (Addis \& Jacobson, 2000; Burns \& Nolenhoeksema, 1991; Detweiler-Bedell \& Whisman, 2005; Kluger \& Karras, 1983). Poor client adherence can hinder even the most efficacious of psychological programmes, often resulting in poor use of resources, staff and client time, and increased costs associated with treatments (Chen, A., 1991). As such, client adherence is an important issue for researchers and clinicians.

\subsection{Psychology and Technology}

The use of technology is becoming increasing prevalent throughout psychological research and practice. Psychological interventions can now commonly be accessed by internet websites, phone or video conferencing, email, and even chat rooms (Carlbring \& 
Andersson, 2006; Goss \& Anthony, 2009). The advantages of these mediums of communication include greater flexibility in treatment timing; objective assessment of treatment compliance; and increased self disclosure and social support (Bull, Gaglio, McKay, \& Glasgow, 2005; Carlbring \& Andersson, 2006; Casey \& Halford, 2010; Clough \& Casey, 2011). Furthermore, treatments delivered by these means are more easily disseminated and are more cost effective than traditional psychological interventions (Rothbaum, 2004).

There have been numerous reviews conducted of technologically based interventions (e.g., Barak, Hen, Boniel-Nissim, \& Shapira, 2008; Carlbring \& Andersson, 2006). However, a major goal of these technological interventions has often been to replace or duplicate face to face therapy (Clough \& Casey, 2011). The present review focused only on technological adjuncts designed to increase client adherence during traditional face to face psychotherapy. The present review is the first to focus on how technological adjuncts may be able to enhance traditional therapist administered treatments, specifically by increasing client adherence to the therapeutic process.

\subsection{Adherence during Therapy}

An initial comprehensive literature search identified four key areas in which technology has been incorporated to increase adherence to the therapeutic process: dropout and non-attendance, client engagement during and between therapy sessions, aftercare, and adherence with medication regimes. Although technological adjuncts have been widely researched in pharmacotherapy and adherence to prescribed medications (e.g., Kranzler, AbuHasaballah, Tennen, Feinn, \& Young, 2004), this area was deemed to be beyond the scope of the present review.

1.2.1. Dropout and Non-Attendance. Client dropout and non-attendance are two forms of non-adherence that are common throughout psychological practice. Although they are similar concepts, the two should be distinguished in research. 
Dropout is defined as client termination of treatment before the completion of the therapy programme (Barrett, Chua, Crits-Christoph, Gibbons, \& Thompson, 2008; Melville, Casey, \& Kavanagh, 2007; Ogrodniczuk, Joyce, \& Piper, 2005). It is however unclear as to what defines a complete treatment programme. While some studies have defined dropout as client termination of treatment before the therapist believes they are ready to do so (MacNair \& Corazzini, 1994), others have defined dropout as client termination of therapy prior to attending a set number of sessions (Baruch, Vrouva, \& Fearon, 2009). Although the latter definition provides a more objective method of assessing dropout, there are discrepancies as to how many sessions constitute a complete programme. Depending on the definition of dropout, it has been estimated that approximately 40-60\% of individuals attending mental health clinics dropout before completion of treatment (Baruch et al., 2009).

Non-attendance, or no-show, is client failure to attend booked appointments. Nonattendance is often the first step towards dropout, and as such some studies fail to make the distinction between the two. The percentage of non-attended scheduled appointments in mental health settings has been estimated to be as high as $60 \%$, with an average of about a third of appointments not kept (Lefforge, Donohue, \& Strada, 2007). Non-attendance increases the length of waiting lists, leads to poor use of staff time and resources, loss of income for therapists and clinics, and compromises the effectiveness of treatment programmes (Chen, A., 1991; Conduit, Byrne, Court, \& Stefanovic, 2004; Lefforge et al., 2007). Indeed, failure to attend regular appointments has been associated with increased relapse rates during aftercare, higher patient rates of psychological distress, and can precipitate other no-shows and dropouts in group therapy (Chen, A., 1991; Winston, Pardes, Papernik, \& Breslin, 1977).

1.2.2. Engagement during therapy sessions. Engagement during sessions can relate to emotional disclosure (Murdoch \& Connor-Greene, 2000), participation in exposure tasks 
(Abramowitz, Franklin, Zoellner, \& DiBernardo, 2002) or other in therapy activities and processes. Engagement and adherence to tasks in session has been associated with better treatment outcomes (Abramowitz et al., 2002), and enhanced therapeutic alliance (Loeb et al., 2005). Whilst adherence during therapy sessions has been linked with personality traits such as avoidance and dependence, it has not been associated with symptom severity (Edelman \& Chambless, 1995).

1.2.3. Engagement between therapy sessions. Engagement between sessions is most commonly conceptualized as homework compliance or homework adherence. Homework is an important part of many therapy styles, providing continuity between sessions and allowing clients to apply therapeutic techniques in real world settings (Freeman \& Rosenfield, 2002). Although commonly associated with cognitive behavioural approaches to therapy (Beck, Rush, Shaw, \& Emery, 1979), homework is now found in client centred psychotherapy, experiential therapy, interpersonal therapy, and couple and family therapies (Kazantzis \& Ronan, 2006).

Homework adherence has been related to treatment outcome in a linear fashion, with greater adherence being associated with greater outcomes (Scheel, Hanson, \& Razzhavaikina, 2004). Furthermore, structural equation modelling has found this relationship to be causal (Burns \& Spangler, 2000). Homework adherence may also help reduce client dropout, with greater adherence early in therapy being associated with better retention during treatment (Gonzalez, Schmitz, \& DeLaune, 2006). Indeed, homework compliance may have the strongest relationship to outcome during the first few sessions of treatment (Westra, Dozois, \& Marcus, 2007). Adherence has also been associated with better outcomes after treatment has finished, indicating that homework may be particularly important for client success when the therapist is no longer present (Edelman \& Chambless, 1995). 
Homework adherence has been positively associated with patient motivation (Helbig \& Fehm, 2004) and dependent personality traits (Edelman \& Chambless, 1995), but not associated with symptom severity (Carroll, Nich, \& Ball, 2005) or locus of control (Leung \& Heimberg, 1996). Homework adherence is also not associated with client educational background, baseline level of coping skills, source of referral, level of motivation, or self efficacy (Carroll et al., 2005).

1.2.4. Aftercare. Aftercare refers to the ongoing psychological care of patients following discharge from inpatient or intensive outpatient treatment programmes (Lash \& Blosser, 1999). The purpose of aftercare is to maintain psychological gains made in primary treatment and to prevent relapse (McKay et al., 1998). Golkaramnay et al. (2007) report that while considerable gains are made during inpatient treatment, a substantial amount of these are often lost in the first 12 months following discharge. The first month after discharge has been identified as a critical period when problems may occur and risk of relapse is highest (Ilgen, Hu, Moos, \& McKellar, 2008; Ramana, Paykel, Melzer, Mehta, \& Surtees, 2003).

Participation in aftercare programmes, whether structured or unstructured, has been associated with increased likelihood of maintaining, and possibly enhancing, treatment gains (Kobelt \& Schmid-Ott, 2010; Sannibale et al., 2003). However, it has been reported that as many as $70 \%$ of patients fail to make even their first post-discharge appointment (Klinkenberg \& Calsyn, 1996). Patient adherence and engagement with aftercare plans have proven problematic for clinicians (Chen, A., 1991).

\subsection{Theories of Adherence}

Many theories of adherence have been proposed throughout the literature. The purpose of the present section was to provide brief overviews of three of the dominant theories of adherence. The purpose of these overviews was not to critically discuss these theories in 
detail, but rather to provide a means of understanding the concept of adherence, as well as the mechanisms involved in increasing adherence.

1.3.1. The Transtheoretical Model. The most popular theory within the field of psychological adherence has been the Transtheoretical Model (TTM) developed by Prochaska \& DiClemente (1983). The TTM was originally intended to draw theories of behaviour change together in a single system, and consisted of 14 components (Armitage, 2009). The most well known components are the stages and processes of change. The model consists of six stages of change and ten processes of change (Prochaska \& Diclemente, 1983; Prochaska \& Velicer, 1997). According to the TTM, individuals progress through the various stages of change toward lasting behaviour change. As such, clinical interventions should be tailored to meet the client's current stage of change.

Although the TTM, and in particular the stages of change, have been widely popular within health and clinical psychology, the model has been the subject of some criticism. Research has found limited evidence of stage based interventions being any more successful than usual care or no intervention (Bridle et al., 2005; Horowitz, 2003; Riemsma et al., 2002). Furthermore, there has also been limited evidence explaining the transition and divides between stages (Armitage, 2009; West, 2005a). Data would suggest that it is possible for patients to be in several stages at once; a concept which is inconsistent with the model (Drieschner, Lammers, \& van der Staak, 2004). Such criticisms of the TTM have led to a divide in opinion among researchers and clinicians, with some arguing that the TTM should no longer be used in research or practice (West, 2005b).

1.3.2. Self Determination Theory. Self Determination Theory (SDT) is a broad macro theory of psychological and health care motivation (Deci \& Ryan, 2000, 2008). The SDT asserts that people may experience three different types of motivation; intrinsic, extrinsic, and amotivation (Ryan \& Deci, 2000). 
Intrinsic motivation refers to a person's innate tendency to seek out and explore novel and new experiences (Ryan \& Deci, 2000). Intrinsic motivation aims to fulfil the three innate psychological needs of competence, autonomy, and relatedness. Conversely, extrinsic motivation results from separable outcomes which are associated with performance of the activity (Ryan \& Deci, 2000). It differs from intrinsic motivation in which the activity is performed because of the inherent satisfaction it provides. Extrinsic motivation is based upon four different regulatory styles, ranging from external regulation to integrated regulation (Ryan \& Deci, 2000). These regulatory styles represent the varying extent to which behaviour is perceived as being autonomous. The third type of motivation, amotivation, is the state of lacking intent to act (Deci \& Ryan, 2008).

Ryan and Deci (2008) have proposed that clinical outcomes may be optimal when individuals are internally motivated in the therapeutic process, with internal motivation leading to integrated learning and behaviour change. Furthermore, the SDT may provide a rationale as to the effectiveness of motivational interviewing (Ryan \& Deci, 2008).

Support for SDT has come from studies in fields such as online learning (Chen, K. C., \& Jang, 2010), glycemic control behaviours (Williams, McGregor, Zeldman, Freedman, \& Deci, 2004), tobacco cessation (Williams et al., 2006), maladaptive weight control behaviours (Thogersen-Ntoumani, Ntoumanis, \& Nikitaras, 2010), video game engagement (Przybylski, Rigby, \& Ryan, 2010), work practices (Kuvaas, 2009), and dental treatment and hygiene (Halvari, Halvari, Bjornebekk, \& Deci, 2010). However, the theory has also been criticised for not taking into account the social motivations and social processes of human behaviour (Buunk \& Nauta, 2000). It has also been argued that the evidence base behind the selection of the three innate psychological needs is not strong, and may not take into account cultural and individual differences relating to these needs (Buunk \& Nauta, 2000; Carver \& Scheier, 2000). 
1.3.3. The Theory of Planned Behaviour. The Theory of Planned Behaviour (TPB) (Ajzen, 1985, 1991) was developed from the earlier Theory of Reasoned Action (Fishbein \& Ajzen, 1975). The two theories share the assumption that intentions are the immediate antecedents to behaviour. That is, the stronger the intention to perform a behaviour, the greater the likelihood of the behaviour actually occurring (Doll \& Ajzen, 1992). The TPB is designed to predict and explain human behaviours in specific situations (Ajzen, 1991).

According to the TPB, behavioural intentions are influenced by attitude toward the behaviour, subjective norm, and perceived behavioural control (Ajzen, 2002; Madden, Ellen, \& Ajzen, 1992). Attitude toward the behaviour refers to how positively or negatively a person evaluates the target behaviour, whilst subjective norm refers to perceived social pressure to perform or not perform the behaviour (Ajzen, 1991). Perceived behavioural control refers to the ease or difficulty with which the individual believes they can perform the behaviour. These three antecedents to intentions are argued to develop from beliefs, such as behavioural beliefs, normative beliefs and control beliefs (Ajzen, 1991).

According to the TPB, client intentions will be predictive of treatment adherence provided that clients have volitional control over treatment behaviours. Client intentions toward engaging in treatment behaviours may be improved by assessing client beliefs about subjective norms and perceived behavioural control, as well as implementing interventions to increase positive attitudes toward the treatment behaviours.

The TPB has been used for research in the prediction of health behaviours, such as diet (Conner, Kirk, Cade, \& Barrett, 2003; White, Terry, Troup, Rempel, \& Norman, 2010), child immunisation rates (Tickner, Leman, \& Woodcock, 2010), exercise (Nguyen, Potvin, \& Otis, 1997), condom use (Albarracin, Johnson, Fishbein, \& Muellerleile, 2001), and smoking behaviours (Kam, Matsunaga, Hecht, \& Ndiaye, 2009; Nehl et al., 2009). The efficacy of the TPB has been supported by empirical studies (e.g., Armitage \& Talibudeen, 2010; Doll \& 
Ajzen, 1992), and a meta analysis (Armitage \& Conner, 2001). Doll and Ajzen (1992) have also found that direct experience with a behaviour increases the predictive ability of behavioural intentions as well as the temporal stability of attitudes. Over the past 20 years the TPB has been a popular and influential behavioural theory within psychology and healthcare, and has shown strong predicative abilities for healthcare behaviours.

1.3.4. Theories and the present review. The three theories of adherence discussed in this paper have been useful in understanding and researching client adherence in clinical practice. The present review of technological adjuncts to increase adherence to therapeutic processes is discussed with reference to these theories of adherence, with a focus on the TPB.

\subsection{The Current Review}

The studies included in this review were selected on the basis that they were aimed at enhancing client adherence to therapy with the use of technological adjuncts. That is, the aim was to improve adherence within therapist administered treatments, rather than maintaining adherence whilst reducing therapist time with the client or changing the medium of therapist communication (e.g., webcam or email). The focus in this review was on clinical applications, and thus studies from areas such as experimental, neuropsychology, health, or organisational psychology were excluded.

Database searches were conducted for articles published between the years of 19902010, using the databases of PsycINFO, Web of Knowledge, and ProQuest Psychology Journals. Search terms were (psychotherapy, psychology, counselling or counseling) paired with key terms for each of the three areas; dropout and non-attendance (dropout, nonattendance, reminder/s, or prompt/s), engagement during and between therapy sessions (engagement, homework, extratherapy, extratreatment, home practice, or self help assignments), and aftercare (aftercare or continuing care). Where sufficient data was provided, Cohen's $d$ was calculated as a measure of effect size. 


\section{Dropout and Non-Attendance}

To date, research has found no definitive cause of dropout or non-attendance. However, certain client characteristics have been associated with increased risk. These characteristics include having a current diagnosis of substance abuse disorder (El-Mallakh et al., 2004), borderline personality disorder (Marini et al., 2005), being female, young, with a previous history of defaulting during treatment (Chariatte, Berchtold, Akre, Michaud, \& Suris, 2008; Marini et al., 2005), or having a longer duration of illness or current family distress (Hoste, Zaitsoff, Hewell, \& le Grange, 2007). Other social factors have also been linked with increased risk for dropout and non-attendance, such as minority status, economic disadvantage and limited education (Arnow et al., 2007; Barrett et al., 2008). However, research is in large part still inconclusive, and sometimes even conflicting (Arnow et al., 2007). Yet, one factor that has been linked consistently with increased risk for dropout and non-attendance is time spent on waiting lists, with longer waits associated with poorer outcomes (Bender \& Koshy, 1991; Festinger, Lamb, Marlowe, \& Kirby, 2002).

\subsection{Interventions}

Current interventions to combat dropout and non-attendance have been categorized into nine strategic categories; pretherapy preparation, patient selection, time-limited or shortterm contracts, treatment negotiation, case management, appointment reminders, motivation enhancement, facilitation of the therapeutic alliance, and facilitation of affect expression (Ogrodniczuk et al., 2005). Despite these strategies, dropout and non-attendance remain a problem for many psychology clinics (Ogrodniczuk et al., 2005). Technological adjuncts may have the potential to improve current intervention strategies.

\subsection{Appointment Reminders and Prompts}

Appointment reminders and prompts have been researched as one strategy for decreasing no-shows and preventing dropout. This strategy has been in use for over 30 years 
with early research focused on reminders sent by mail, although more recent research has utilized telephone reminders. Fourteen studies were identified as utilizing some form of technological device for delivering prompts, and are summarized in Table 1. Effect sizes were calculated for eight studies. For those studies which utilized chi squared analyses Cramer’s phi $\left(\Phi_{c}\right)$ was used as a measure of effect size.

2.2.1. Effectiveness of telephone reminders. Three studies found appointment reminders to be ineffective in increasing attendance (Kicklighter, 2001; Kluger \& Karras, 1983; Stasiewicz \& Stalker, 1999), whilst the remaining 11 found positive effects associated with the reminders. Appointment reminders were only effective at increasing attendance for initial appointments, not subsequent appointments (Conduit et al., 2004; Shivack \& Sullivan, 1989). Reminders with direct client and direct therapist contact were more effective than indirect reminders, such as letters, recorded messages, or reminder calls made by the clinic secretary (Shivack \& Sullivan, 1989; Shoffner, Staudt, Marcus, \& Kapp, 2007), as were reminders issued temporally close to the appointment date (Hochstadt \& Trybula, 1980). Kluger and Karras (1983) found reminders with an added orientation component, introducing the client to the clinic and outlining what to expect from therapy, were more effective than reminders without the orientation component. However, this finding was not supported by Kourany et al. (1990). In most studies, reminders were also cost effective, and initial outlays were returned by the increase in kept appointments. Indeed, Turner and Vernon (1976) reported that the six monthly cost of their telephone reminder intervention was recovered with only six extra kept appointments.

2.2.2. Relationships with demographic variables. Three studies examined the association between attendance and demographic variables. Conduit et al. (2004) found appointment non-attendance was not related to socioeconomic status (SES). However, authors used appointment fee as a measure of SES, which may have been less than an optimal 
representation. Kourany et al. (1990) also found demographic variables such as age, sex, race, time of appointment and referral source to be unrelated to appointment attendance.

Furthermore, although Watt et al. (2007) found indigenous status and living situation to be related to attendance, other demographic variables such as age, employment, education, and referral source were again not found to be associated. As expected, studies that did examine time spent on waiting lists, found longer waits to be associated with higher non-attendance (Kicklighter, 2001; Stasiewicz \& Stalker, 1999).

2.2.3. Theoretical explanations. It has been suggested that appointment reminders may be effective because they act as cues to counteract prospective memory failures (Tanke \& Leirer, 1994). This notion is supported by studies which have found the most common reason patients cite for missing an appointment is because they simply forgot about it (e.g., Carrion, Swann, Kellertcecil, \& Barber, 1993). However, this perspective does not explain why the success of appointment reminders appears to be moderated by the type of appointment; that is, why reminders are only successful at improving attendance for initial appointments. This effect is also not easily understood by the theoretical approaches of TTM or SDT.

Martinez and Wong (2009) have suggested that the relationship between reminders and type of appointment can be understood by social and operant learning theory. According to this theory, behaviour is affected by the antecedent and consequent stimuli that immediately precede and follow the target behaviour. That is, antecedent stimuli affect the behaviour by reliably predicting the consequences of the behaviour (Kirsch, Lynn, Vigorito, \& Miller, 2004).

In the context of therapy, the reminders (antecedent stimuli) will be effective in increasing appointment attendance (target behaviour) provided the clients receive some benefit from their attendance (consequent stimuli) such as useful information, alleviation of 
symptoms or emotional support (Martinez \& Wong, 2009). If the antecedent prompts have no value in predicting the consequent stimuli, that is, if patients no longer find the therapy sessions rewarding, then the prompts will eventually be ignored by the client (Martinez \& Wong, 2009). Therefore, clients may fail to attend after the initial appointment because the therapy is not meeting their expectations or needs, and thus the antecedent stimulus is no longer a reliable predictor of the consequent stimuli.

Similarly, the TPB may also be useful in understanding the relationship between appointment reminders and attendance. It may be that client intentions to attend treatment sessions change following the first appointment session. Indeed, direct experience with a behaviour is believed to increase the predictive ability of the behavioural intention (Doll \& Ajzen, 1992). Therefore previous experience with therapy may change perceived behavioural control, social norms, or even attitudes toward the behaviour through social and operant learning theory. It may be beneficial for therapists to discuss possible barriers concerning social norms and perceived behavioural control during the first appointment. Taken together, a measure of the three antecedents to behavioural intentions may be a useful predictor of subsequent appointment attendance.

Although many studies have examined the relationship between client attitudes, satisfaction and dropout, most of these ratings are usually taken retrospectively after dropout (Carrion et al., 1993), or immediately before weekly psychotherapy sessions (Harmon et al., 2007; Lambert, Harmon, Slade, Whipple, \& Hawkins, 2005). Both of these methods may fail to capture actual client satisfaction with the current therapy session, and whether it relates to attendance at the following session. Confidential client feedback taken immediately after individual therapy sessions may provide valuable insight into this relationship.

2.2.4. Limitations and directions. Although these studies demonstrate that appointment reminders may be an effective means of increasing appointment attendance, 
there have been limitations with current research. Many of the studies fail to examine demographic variables, and there is often a lack of detail in reporting methods, including exactly when reminders were issued in relation to the appointments. Furthermore there is a lack of randomised controlled trials conducted with appropriate statistical analyses. Some of the studies also failed to examine the individual treatment effects of reminders, separate from other non-attendance interventions (Lash \& Blosser, 1999; Martinez \& Wong, 2009).

Some researchers have also experienced difficulties in implementing the interventions. Hochstadt and Trybula (1980) experienced initial enthusiasm from clinicians toward the telephone reminder intervention. However as the intervention became successful, clinician enthusiasm waned as many had become reliant on no-show time for completing other tasks. Kluger and Karras (1983) found only 50-60\% of clients could be reached by telephone at the times calls were made. This difficulty in reaching clients is likely to be common as reminder calls are most often made during business hours. A possible technological solution to this problem may be to send reminders via mobile phone text messaging or even email. The asynchronous nature of these two mediums of communication allows clients to read and respond in their own time (Boschen \& Casey, 2008). Text message reminders are already being used routinely in medical settings, and have been found to be effective at increasing appointment attendance (Downer, Meara, \& Da Costa, 2005; Leong et al., 2006; Milne, Horne, \& Torsney, 2006). To date, the use of text message reminders has yet to be reported in the psychological literature.

Indeed, technology could be utilized further by incorporating orientation components into electronic reminders. Orientation components often contain information about the clinic, staff, and what to expect during therapy and the first appointment. Some studies have found orientation statements to further improve the effectiveness of mailed reminders (Kluger \& Karras, 1983; Swenson \& Pekarik, 1988). This relationship could be tested by adding 
multimedia orientation components to text messages or emails. Like written orientations, a multimedia orientation could introduce clients to the clinic and staff, as well as outline what to expect from the therapeutic process; all before therapy has begun. This orientation may however be much more realistic and accurate than written orientations, and as such may be more effective.

\subsection{Electronic Questionnaires}

Standardised questionnaires are regularly used as a means of diagnosing, monitoring, and assessing patient progress and psychological functioning. Recently, researchers have begun to develop electronic versions of many established questionnaires. These versions often save time in data coding and analysing, and allow for instantaneous review of data sets. The Outcome Questionnaire - 45 (OQ-45), is one such measure that is now available in electronic form.

The OQ-45 is designed to track patient progress during and following therapy, and to identify those patients at risk for deterioration or dropout (Lambert et al., 2005). Questionnaire items measure four constructs; psychological disturbance, interpersonal problems, social role functioning, and quality of life. Based on the formula for reliable change (Jacobson \& Truax, 1991) therapists can monitor whether patients are improving, not responding or deteriorating from week to week (Vermeersch, Lambert, \& Burlingame, 2000). Therapists can also compare an individual patient's progress to expected patient progress, as represented by recovery curves (Lambert, Hansen, \& Finch, 2001). This feedback has been found to improve patient outcomes for non responsive patients, by allowing therapists to change tactics before the client drops out of treatment (Lambert et al., 2001; Lambert et al., 2005).

One recent technological advance in this system has been the development of the OQAnalyst software. This software allows electronic administration of the OQ-45. Prior to each 
therapy session, patients complete the questionnaire on palm held computers and data is then transmitted instantaneously to the therapist's computer (Lambert et al., 2005). This method of administering the OQ-45 saves time in scoring and analysing data, and also improves dropout prevention strategies by alerting therapists to treatment deterioration prior to the commencement of sessions. The development of the OQ-Analyst software is an example of how technology can be implemented in psychological practice to improve dropout prevention techniques, and increase client adherence to therapy.

\subsection{Future Research}

Technological adjuncts have great potential for use in targeting client dropout and non-attendance. Research in this area has thus far been limited. Of the nine strategic approaches outlined by Ogrodniczuk et al. (2005), to date, technology has only been used for appointment reminders and patient selection. However there are many more ways that technology can be utilized to decrease dropout and non-attendance.

Technological adjuncts could be used to enhance pretherapy strategic methods. Current pretherapy strategies include vicarious pretraining, where the patient is provided with examples of therapy, and experiential pretraining where the patient experiences a simulation of therapy (Ogrodniczuk et al., 2005). Both strategies have shown positive results in reducing dropout and non-attendance (e.g., France \& Dugo, 1985; Piper, Debbane, Garant, \& Bienvenu, 1979)

Technological adjuncts could greatly enhance vicarious pretraining by providing prospective clients with digital therapy examples rather than the traditional audiotape, videotape or written materials sent to clients. Indeed, these digital examples could be mailed to clients in the form of DVDs or CDs, emailed to clients as digital attachments, or played through dedicated websites. Examples could be designed to be interactive, and provide clients with much more realistic demonstrations of appropriate therapist and client behaviours. 
Digital simulations could also improve experiential pretraining by enhancing traditional role playing methods. This could be further enhanced by the use of virtual reality technology, which would allow client immersion in virtual therapy settings.

Appointment reminder strategies could also be enhanced by incorporating text messaging and email reminder systems, as previously discussed. These reminders could include multimedia components which may act as clinic orientations. These types of reminders also have the advantage of being instantaneous, and allow for asynchronous responses outside of normal business hours. Tailored reminder messages may also facilitate early development of the therapeutic alliance, another strategy often employed to decrease dropout.

\section{Client Engagement During and Between Therapy Sessions}

\subsection{Review of the Literature}

Six studies were identified as utilizing technological adjuncts to increase client engagement during and between therapy sessions. These studies are summarized in Table 2 . Effect size could only be calculated for one study.

3.1.1. Client engagement and computer games. Adolescence has been noted as a time of stress for many individuals, however the majority of disturbed adolescents do not receive professional mental health care (Coyle, Matthews, Sharry, Nisbet, \& Doherty, 2005). Of those that do receive care, many are obliged into therapy programmes by their parents (Griffiths, 2004), and may be resistant toward therapists (Clarke \& Schoech, 1994). Computer and video games have been identified as a method of increasing engagement with adolescent clients.

It has been noted that one of the best methods for ensuring the transfer of problem solving skills from therapy situations into real world situations is by presenting adolescents 
with situations that resemble real problems (Favelle, 1994). Video games can provide these realistic real world scenarios, which can be experienced within the safety of the game (Favelle, 1994). Other advantages include that the therapist is able to observe the child's problem solving skills, ability to foresee consequences, hand eye co-ordination, aggression, impulse control, and ability to deal with success and defeat (Gardner, 1991).

“Treasure Hunt” is a psychotherapeutic computer programme developed by researchers in Switzerland (Brezinka, 2008). Although originally developed for the delivery of electronic homework assignments, the game was also utilized to encourage client engagement during therapy sessions. "Treasure Hunt” is an interactive adventure game with multiple levels, and is based on the principles of cognitive behavioural treatment for children. The game was not designed to be a self help tool, but rather to be used as an adjunct during the normal therapy process for use among children and adolescents with internalizing or externalizing disorders. Concepts taught in therapy, such as automatic thoughts and the influence of thoughts on feelings, can be reinforced between sessions in a manner that is fun and attractive to children.

An early pilot study (Brezinka, 2008) revealed that therapists and clients responded well to the programme. Therapists reported that the game was useful in structuring therapy sessions, designing new homework assignments based on the characters and concepts in the game, and also acted as a reward for children at the end of therapy sessions. Children reported that they liked to work with the game and found it enjoyable. Unfortunately no data was collected or analysed during the pilot study. As such it is unclear whether this technological adjunct increased client engagement, or the types of disorders in which it may be beneficial. However the initial report is promising and further investigation is warranted. Coyle and colleagues (Coyle et al., 2005) have also developed a computer game for use in psychotherapy with children and adolescents. This game, "Personal Investigator”, links 
the goal oriented style of computer gaming with that of Solution Focused Therapy. Clients take on the role of investigator, with the aim of finding solutions to personal problems. Adolescents move through various levels of the game which are set in a detective academy. In collaboration with the therapist, the adolescent sets their own therapeutic goals, and is taught such skills as recognising strengths, identifying people in their lives who can support them, and learning new coping strategies. The game was designed to be used during therapy sessions with the therapist acting as a partner for the adolescent Personal Investigator.

Coyle et al. (2005) report four case studies involving the use of Personal Investigator. Adolescents had mental health problems ranging from anxiety and behaviour problems to attempted suicide and difficulties with social skills. All therapists rated the game as being easy to integrate into therapeutic work and helpful in engaging adolescents in therapy. Therapists thought the game was particularly helpful for keeping clients focused on therapeutic tasks for the duration of the therapy session, whilst also keeping the sessions fun and enjoyable for the clients. All four adolescents found the game easy and fun to use, and would recommend the game to other adolescents. Unfortunately no statistical analyses were conducted and the study also lacked a control group. Therapists also experienced technical difficulties with each therapist experiencing a software crash at least once.

One other study utilized a video game based on cognitive therapy principles for the treatment of adolescents with low impulse control (Clarke \& Schoech, 1994). Participants explored an underground cave and were required to make choices relating to specific scenarios. When a correct choice was made points were added to the participants score, and conversely points were deducted when an incorrect decision was made. Clarke and Schoech (1994) found adolescents became more cooperative and enthusiastic about treatment, and attendance in therapy increased following introduction of the video game adjunct. These 
studies (Brezinka, 2008; Clarke \& Schoech, 1994; Coyle et al., 2005) are examples of how video game software may be used to enhance client engagement during treatment.

Unlike the previously discussed studies requiring specialised software, Gardner (1991) made use of Nintendo games such as Mario Bros and Zelda to place the therapist on common ground with child clients. Gardner (1991) found participants gained better social skills, increased in self efficacy and decreased anxiety. Participants also gained better impulse control and became more engaged during therapy sessions. However, no statistical analyses were conducted, nor was there a control group or multiple baselines design.

Computer and video games may be promising technological adjuncts to increase client engagement during therapy. In accordance with the TPB, it may be that these games positively influence clients’ attitudes towards therapy and thus create more favourable behavioural intentions toward participating and engaging in therapeutic tasks. However there is a current lack of randomised controlled trials and standardised programmes available in this field.

3.1.2. Client engagement and email. To date email has been used predominately in psychotherapy as a replacement for traditional face to face therapy (e.g., Titov et al., 2009). However, it has yet to be thoroughly investigated as an adjunct in the therapy process, particularly for increasing client engagement. Murdoch and Connor-Greene (2000) report that email may be useful in prompting patients for homework reports, providing more frequent feedback on homework, and to encourage reflection. Patients are able to save therapist's emails and reread them as needed. Time can also be taken in formulating responses, which may encourage deeper thinking and understanding. All of these strategies may encourage patients to engage in therapy related thinking and activities between sessions, and may strengthen the therapeutic alliance and increase engagement within sessions. 
Murdoch and Connor-Greene (2000) report two case studies involving the use of an email component additional to normal therapy. The first case presented was that of a young female suffering depression. The patient initially had difficulty self disclosing during therapy sessions and only completed a quarter of homework tasks. No significant changes were observed during the first 14 weeks of therapy, following which the patient was asked to email homework assignments to the therapist each working day. If assignments were not received by midday the therapist was able to email the client prompting for completion of the homework.

The patient reported feeling more comfortable disclosing to the therapist in emails than in person, and this increased self disclosure was eventually continued into therapy sessions. The therapist was also able to provide more timely feedback on homework tasks, encouraging the patient to continue progressing. The researchers report that symptom severity decreased dramatically following the addition of the email component to therapy, and contend that this was a result of increased client engagement during and between therapy sessions.

The second case study reported by Murdoch and Connor Greene (2000) involved the treatment of a young female presenting with an eating disorder. This patient displayed a consistent pattern of responding well to therapy in the days immediately following each session, but then deteriorating up until the next therapy session. After nine weeks of therapy an additional email component was introduced whereby the patient was asked to email the therapist each day reporting on behavioural progress and thinking patterns. The client reported finding this extremely helpful and began to discuss family conflicts in greater depth during the emails, which then also led to increased self disclosure during the weekly therapy sessions. Following the implementation of the email component the patient was able to maintain therapeutic gains throughout the week between regular therapy sessions. 
The two case studies presented in by Murdoch and Connor-Greene (2000) demonstrate how email may be valuable for increasing client engagement between therapy sessions, which may also lead to increased engagement during therapy sessions. These cases are however lacking in that they contained no control group or multiple baselines design, and no formal statistical analyses were conducted. Further research is required. In accordance with the TPB, it may be that participants have a more favourable behavioural intention toward electronic homework tasks, due to positive social norms surrounding the use of email in everyday life.

3.1.3. Client engagement and computer based training. One study describes the development of a computer delivered homework component for the treatment of substance addiction (Carroll et al., 2008). “CBT4CBT” was developed as an additional adjunct to cognitive behavioural treatment of drug dependency.

The programme covered such concepts as coping with craving, refusing offers of drugs and alcohol, and improving decision making skills (Carroll et al., 2008). Material was presented in a variety of formats including verbal instructions, voiceovers, interactive assessments, video examples, graphic illustrations, and practice exercises. Participants were randomly assigned to treatment as usual and CBT4CBT conditions. All participants were offered weekly individual and group sessions of general drug counselling, and were also tested twice weekly for traces of drugs and alcohol. Those in the experimental condition were also offered the use of the CBT4CBT programme between therapy sessions, run on private computers within the clinic.

Participants in the experimental group tested positive for drugs significantly fewer times than those in the treatment as usual condition (Carroll et al., 2008). Those in the experimental group also reported longer periods of abstinence from drugs. Treatment involvement and homework completion were strongly related to treatment outcome, but only 
in the CBT4CBT condition. The best indicator of treatment outcome for the control condition was severity of baseline symptoms. These results provide a link between the programme and outcome, and support for the use of such technological adjuncts to increase client engagement.

\subsection{Limitations}

Current research is limited by a lack of appropriately conducted randomised controlled trials. Indeed, of the six studies reviewed in this section, only one contained a control group or conducted any formal analyses.

Research in the use of video games to increase engagement has been promising; however these results are limited due to a lack of psychotherapeutic games that are readily available to practising clinicians. Indeed, much of this research remains in experimental settings. Although one study made use of commercially produced video games (Gardner, 1991), as yet there is no guide for clinicians as to which games may be appropriate during therapy. It is highly unlikely that many practising clinicians will purchase and work through a variety of computer games to find the right ones for specific clients. Future research should focus on the development of psychotherapeutic computer games that may be made widely available to clinicians, and in the development of guides for the use of commercially produced games.

There are also limitations associated with the use of email technology. Although the researchers in the Murdoch and Connor-Greene (2000) study reported that reading and responding to individual client emails took approximately 10 minutes per day, this time may easily add up for clinicians seeing several clients per day. Indeed, this additional 10 minutes per client per day could easily add hours per week to the average clinicians work load. Therefore, while this technological adjunct may be useful for increasing self disclosure and engagement, it may be that it is best reserved for those particular clients struggling to make 
gains during traditional therapy programmes. Emails also present issues surrounding confidentiality and psychiatric emergencies. Appropriate guidelines must be developed surrounding the use of such adjuncts and must adhere to governing privacy rules concerning the electronic exchange of healthcare information (Fisher \& Oransky, 2008). Clinicians may also find it beneficial to discuss some of these issues with clients before introducing an email component to therapy.

\subsection{Future Research}

Aside from those limitations present in the current body of research, there are also a variety of other ways research in this field should be expanded. Homework adherence has been identified as a critical factor affecting the success of many forms of therapy. Yet despite the increase in technological adjuncts within psychology, many homework assignments are still delivered by pen and paper. Clients are often required to complete thought and mood charts in paper diaries, and records of relaxation exercises are also still recorded manually. Many of these homework tasks could be converted to an electronic format that the client could complete via computer, personal digital assistant (PDA) or even "Smartphone”.

Completing tasks electronically using a device such as the Smartphone holds many advantages (Clough \& Casey, 2011). Clients would be able to complete homework tasks when and wherever they choose, making responses more ecologically valid. Furthermore, completing assignments this way is more discreet than by traditional methods, and may also be more enjoyable for the client. Responses may be sent to the therapist automatically, and the therapist can prompt clients for missing responses. All of these factors may lead to increased homework adherence.

Psychologically based video games may also be delivered by portable devices such as the Smartphone or PDA. As these games have shown promise in increasing engagement during therapy sessions, it may also be possible that they may increase engagement and 
homework adherence between sessions. Clinicians may find that adolescents may be much more likely to complete a certain level of a game as homework, rather than a paper based assignment which may be associated with school homework tasks.

Another issue that may warrant further attention is whether the implementation of such adjuncts are susceptible to reactivity, such as the Hawthorne effect (Landsberger, 1958). It may be that the addition of a new and novel experience to the therapeutic process, or perhaps an overall sense of the therapist "watching”, is enough to increase client engagement regardless of the therapeutic content. An interesting design may be to examine client adherence when a video game is implemented under psychotherapeutic or nonpsychotherapeutic conditions. However, even if reactivity effects partly account for improved outcomes observed in technologically enhanced therapies, this reactivity does not represent a limitation. It may ultimately be useful to conceptualize use of technology adjuncts as involving both common and specific factors in a way that is analogous to perspectives on change factors involved in therapy (Buckley, 2008; Casey, Oei, \& Newcombe, 2005). It may however be of theoretical interest to identify the specific treatment effects of the adjuncts compared with any reactivity effects.

\section{Aftercare}

As discussed previously, client adherence with aftercare programmes can be a significant challenge for therapists. Feedback, prompts, and adherence contracts have all been associated with increased utilization of psychological aftercare (Lash, 1998; Lash \& Blosser, 1999). Patient variables such as self efficacy (Vielva \& Iraurgi, 2001), employment status and nature of psychological complaint (Owen, Rutherford, Jones, Tennant, \& Smallman, 1997), as well as history of prior hospitalizations, less denial of illness, high scores on scales measuring helplessness and hopelessness, and longer length of hospital stay have also been 
associated with increased utilization of services (Chen, A., 1991). Lastly, therapist continuity and fewer days between discharge and first appointment have also been associated with increased engagement in aftercare (Chen, A., 1991). To date, little research has been conducted assessing how technology may be able to increase adherence to psychological aftercare programmes.

\subsection{Review of the Literature}

Five studies were identified as incorporating technology to increase patient adherence to psychological aftercare programmes, and are summarised in Table 3. Effect sizes were able to be calculated for two studies.

4.1.1. Aftercare and online chat. Online chat has recently been used in the delivery of aftercare services (Golkaramnay et al., 2007). The most common form of aftercare usually involves a shift from inpatient psychological care to outpatient appointments. However, as Golkaramnay et al. (2007) report, this treatment is not always readily available due to long waiting lists for outpatient services.

Golkaramnay and colleagues (2007) compared the efficacy of an aftercare online chat intervention to treatment as usual. Participants were patients transitioning from inpatient to outpatient care at a German psychiatric hospital, and had a variety of presenting complaints including mood and affective disorders, personality disorders, and neurotic and somatoform disorders. Participants were non-randomly assigned to conditions based on whether their health insurance would cover the online aftercare intervention. Those in the online intervention participated in weekly chat sessions with 8-10 other participants also recently discharged from the same psychiatric unit. Groups met in virtual rooms and communicated through written messages. The clinical focus was closely linked to that of face to face group therapy. Both control and experimental groups were able to seek other outpatient psychological services as desired. 
The online intervention was found to be user friendly and was rated positively by $90 \%$ of participants. The researchers also used a global measure of general improvement, identifying any participants that had not shown substantial benefit across a number of the different outcome measures. These cases were labelled as "signal cases". At twelve month follow up the intervention group contained less "signal” cases than the control group, despite the two groups being equal at discharge. The online chat participants were able to better maintain treatment gains and also displayed less psychological stress than control participants. The intervention was well accepted, with session attendance high (85\%) and attrition low (9.4\%). Results were however limited by the non-random assignment of participants to groups. It may also be valuable to assess the exact nature of any aftercare accessed by control participants in the twelve months.

Online chat groups may be a feasible and effective method for promoting maintenance of treatment gains and bridging between inpatient and outpatient settings (Golkaramnay et al., 2007). These programmes may be effective in providing psychological support for participants in the critical first month after discharge, particularly while waiting for outpatient treatment. It should be noted that this treatment option is not likely a replacement for face to face outpatient psychotherapy and may not be appropriate for use in the aftercare treatment of all psychological complaints, such as those where significant suicidal ideation may be a clinical focus. However, the Golkaramnay et al. (2007) study demonstrates that this approach may be able to enhance current aftercare practices under certain conditions.

4.1.2. Telephones and aftercare. Lynch et al. (2010) compared telephone monitoring (TM), telephone monitoring with counselling (TMC), and treatment as usual conditions in an outpatient continuing care programme for alcohol dependence. Treatment as usual consisted of ongoing outpatient psychotherapy of up to four months duration. The 
telephone interventions were added to the programme upon participants completing the first three weeks of outpatient care. The telephone interventions consisted of brief telephone calls with counsellors. Calls were delivered weekly for the first eight weeks, and fortnightly for the remaining 44 weeks of the 18 month trial. In the TM condition calls were a brief structured assessment of current substance use status as well as risk and protective factors. Calls in the TMC condition contained added counselling including monitoring of progress, identification of high risk situations and rehearsal of coping behaviours.

The TMC condition produced significantly improved alcohol outcomes than the TM condition or the outpatient treatment as usual conditions (Lynch et al., 2010). No significant differences were found in alcohol measures between the TM and treatment as usual conditions. These results indicate that the additional counselling delivered by telephone in the TMC condition was able to enhance gains in the outpatient programme, and to help participants maintain these gains over an 18 month period. The Lynch et al. (2010) study demonstrates that brief telephone adjuncts may be able to enhance current aftercare practices in the treatment of alcohol dependence.

Results of the Lynch et al. (2010) study were not however supported by results from Hubbard et al. (2007). Hubbard et al. (2007) also compared the efficacy of standard outpatient aftercare for substance use disorders to combined aftercare and telephone counselling.

Telephone counselling provided positive feedback and encouragement with aftercare compliance, including attendance and participation in outpatient therapies (2007). Calls were made in seven of the 12 weeks following discharge from inpatient or residential treatment. No significant differences were found between groups in measures of self reported aftercare attendance. Attendance data collected in sessions indicated that participants in the telephone 
counselling group attended more aftercare sessions than participants in the treatment as usual group, however this difference was also not significant.

Differences between the two studies include that Lynch et al. (2010) applied more cognitive and psychotherapeutic strategies during the phone calls, rather than the purely compliance encouragement provided by Hubbard et al. (2007). Future research should aim to clarify these effects.

4.1.3. Mobile phones in psychological aftercare. Two recent studies have focused on the use of Short Message Service (SMS) text messaging in the aftercare of bulimic patients (Bauer, Percevic, Okon, Meermann, \& Kordy, 2003; Robinson et al., 2006). The SMS-based aftercare intervention was first offered to 30 patients suffering from bulimia nervosa (BN) in a German hospital (Bauer et al., 2003). The programme lasted six months following inpatient treatment, and aimed to reduce the risk of relapse.

Participants were sent messages once weekly in a standard format relating to their bulimic symptoms. Participants were required to reply to these messages, and were also able to send additional free messages to the researchers throughout the week. The researchers replied with one message per week offering support and advice. These SMS responses were a mixture of pre-programmed and individually tailored components.

Although aggregate data was not available for the initial pilot study, case information was reported from two patients. Results indicated that the SMS aftercare intervention was an appropriate bridge between inpatient treatment and outpatient daily life. The SMS programme helped support patients following psychological treatment, and to help them maintain and consolidate the gains achieved in treatment.

Following the success of the programme in Germany (Bauer et al., 2003), an English version of the intervention was piloted on $21 \mathrm{BN}$ patients in the United Kingdom (Robinson et al., 2006). The programme however, was designed to begin on completion of outpatient 
BN therapy rather than inpatient. The same software and largely the same methodology were used in the UK pilot (Robinson et al., 2006) as in the German pilot (Bauer et al., 2003). However, with low usage and high attrition, the UK pilot was only moderately accepted by participants (Robinson et al., 2006). Less than half of the participants completed the study. The majority viewed the lack of personal contact negatively, and would not recommend the program to others.

Key differences between the two studies are that the German participants were given an introduction to the programme during treatment, whilst the UK participants were not. Furthermore, unlike the German study, participants in the UK pilot were not selected based on symptom severity which may have led to a sample with more severe symptoms. The authors (Robinson et al., 2006) noted that as the SMS programme was a minimal aftercare intervention, it may not have been appropriate for the more severe cases. Such an aftercare programme may also not be appropriate for use in the treatment of all psychological disorders, and as such must be further researched before implementation.

The two studies (Bauer et al., 2003; Robinson et al., 2006) demonstrate that the use of technology in psychotherapy must be well planned and implemented in order to be effective. It is important that clinicians do not "add on" technological adjuncts simply because they are available. Rather, these adjuncts must adhere to the goals and aims of the therapy process, and match the specific characteristics of the client and environment for which they are to be implemented.

\subsection{Limitations}

Current research in this field is limited by a lack of studies with appropriate control comparison groups and random allocation of participants. Indeed, of the three aftercare studies reviewed in this section, only one contained a comparison group (Golkaramnay et al., 2007). This study did not however contain random assignment to conditions. 
The Bauer et al. (2003) and Robinson et al. (2006) studies demonstrate the need for technological adjuncts to be well planned and implemented, rather than on an ad hoc basis. These studies also demonstrate the need for interventions to be matched with patient characteristics such as symptom severity. As these two studies demonstrate, although minimal aftercare interventions may be appropriate for some patients, those with more severe symptoms may require more intensive aftercare programmes.

Indeed, while technologically based aftercare interventions may provide a useful bridge between inpatient and outpatient care, particularly if waiting lists are long, it is unlikely that these chat or text based methods will replace traditional face to face therapy. This may be the case particularly for patients with more severe symptoms or with greater risk factors (McKay, Lynch, Shepard, \& Pettinati, 2005). Indeed the web and text based interventions discussed in this section do not contain protocols for care in psychological emergencies, or for ethical issues such as privacy. The use of such adjuncts must therefore be implemented with respect to the various ethical codes and privacy rules governing healthcare practices. Despite this, these interventions may be useful as additional adjuncts to enhance traditional psychological aftercare programmes, and for patients waiting or unable to access such programmes.

\subsection{Future Research}

There are many directions for future research in this field, such as in the delivery of feedback, prompts, and orientations. These devices have been found to increase participant adherence to aftercare (Lash, 1998; Lash \& Blosser, 1999), although to date they have been delivered only by paper or telephone. Future research could assess whether digital versions of these orientations and prompts could also enhance utilization of psychological aftercare. That is, these orientations and reminders could be sent by email, text message, or multimedia 
message. As discussed with appointment reminders, this may allow for more personalised and expanded delivery of content.

Future studies should also aim to expand upon the work of Bauer et al. (2003) and Robinson et al. (2006) by incorporating mobile phones and Smartphones into aftercare therapy. These studies have demonstrated that bulimic symptoms can be tracked for up to six months after completion of therapy, by means of text messaging. However, it may be possible to track other psychological symptoms via mobile phone as well. For example, standardised questionnaires may be delivered via Smartphone, with responses returned to the therapist by means of wireless internet. This may allow therapists to monitor patients' symptoms on completion of therapy, and throughout aftercare. Therapists may be alerted if the patient is regressing considerably or at risk of relapse. Patients may also be able to access intermittent feedback from therapists by text message, email, or phone call. These services may enhance current aftercare practices and create better continuity for patients during the transition period from inpatient to outpatient.

The work of Golkaramnay et al. (2007) may also be expanded upon by the use of video conferencing. Use of video media would allow for greater expression of emotion and language than in text based chat rooms, and would more closely resemble traditional group therapy. This style of intervention would however require additional resources such as web cams, microphones, and high speed internet. These pieces of equipment could be provided for the duration of aftercare, or to cover the break between discharge and aftercare. However, the provision of such equipment may prove prohibitively expensive for some clinicians, and may also be logistically impractical if the patient is not receiving aftercare from the same source as primary care. Yet for those participants with access to such resources, video conferencing may be a valuable technological adjunct to increase adherence to, and enhance current aftercare programmes. 


\section{General Conclusions}

The purpose of the present paper was to identify and review technologies to enhance current psychotherapy practices with a specific focus on increasing client adherence to therapy. Three theories of psychological adherence were presented and discussed; the TTM, TPB and SDT. Limitations were placed on the content that was reviewed in this paper. Adjuncts designed to replace or reduce direct therapist contact, change the medium of communication between the client and therapist, or alter the content or style of the therapy, were not included in this review. Three areas of adherence were identified, namely treatment dropout and non-attendance, engagement during and between therapy sessions, and aftercare.

Dropout and non-attendance studies were found from the strategic areas of patient selection and appointment reminders. Telephone reminders were effective for increasing attendance at initial but not subsequent therapy appointments. Social and operant learning theory, as well as the TPB may be useful in understanding this reminder effect. It may also be beneficial to assess client attitudes immediately following therapy sessions. Although appointment reminders have been researched for over 30 years, to date no research has examined the efficacy of electronic reminders. Future research should assess the effectiveness of electronic forms of reminders such text and email reminders. Prompts may also benefit from interactive and multimedia components. Multimedia and electronic orientations may increase client attendance at therapy sessions, particularly when using vicarious and experiential pretraining.

Engagement during and between therapy sessions may be improved by the use of emails, video games and computer based training. The field would benefit from the development of a greater number of standardised and widely available psychotherapeutic video games. Electronic homework tasks may increase adherence and client satisfaction, as well as provide greater options for behavioural monitoring, interactive tasks, and relaxation 
exercises. Portable technological adjuncts such as Smartphones and PDAs may be particularly effective in the delivery of such activities. Future research may benefit from examining whether such technological adjuncts may be susceptible to reactivity effects.

Aftercare practices may also be improved by the use of technological adjuncts such as online chat, telephone counselling and SMS interventions. Online video conferencing could extend current research and enhance chat room aftercare for patients awaiting outpatient treatment. Incorporating mobile phones into aftercare may also aid client monitoring, as well as provide an ongoing link for the client once therapy has ceased. These interventions may help bridge the gap between inpatient and outpatient treatment, or outpatient and daily life. Such interventions may improve the effectiveness of aftercare programmes, and assist patients in maintaining treatment gains.

Overall, current research in this field is limited by a lack of randomised controlled trials, standardised interventions, and appropriate data analysis. It is also unclear whether certain technologies may be more amenable to the treatment of specific disorders, or how generalizable current research is among differing treatment modalities, diagnoses, and severities. This field is still a relatively new field in psychology, and there is considerable of scope for further research. Indeed, although some of the techniques discussed in this paper were available 20 to 30 years ago, many are only now becoming increasingly adopted and researched within clinical psychology. With the expansion of this field also comes new challenges in ensuring appropriate levels of privacy and security of patient information. It is important for such adjuncts to be implemented with respect to current ethical and privacy rules concerning healthcare communications and treatment guidelines. Above all, such adjuncts should only be implemented with the informed consent of the patient.

Current research has indicated a great potential for technological adjuncts to enhance current psychotherapy practices by increasing client adherence to the therapeutic process. 
Developments in this field will not only provide greater options for clinicians, but increased care for clients. 


\section{References}

Abramowitz, J. S., Franklin, M. E., Zoellner, L. A., \& DiBernardo, C. L. (2002). Treatment compliance and outcome in obsessive-compulsive disorder. Behavior Modification, 26(4), 447-463.

Addis, M. E., \& Jacobson, N. S. (2000). A closer look at the treatment rationale and homework compliance in cognitive-behavioral therapy for depression. Cognitive Therapy and Research, 24(3), 313-326.

Ajzen, I. (1985). From intentions to actions: A theory of planned behavior. In J. Kuhl \& J. Beckmann (Eds.), Action-Control: From Cognition to Behavior (pp. 11-39). Heidelberg: Springer.

Ajzen, I. (1991). The theory of planned behavior. Organizational Behavior and Human Decision Processes, 50(2), 179-211.

Ajzen, I. (2002). Perceived behavioral control, self-efficacy, locus of control, and the theory of planned behavior. Journal of Applied Social Psychology, 32(4), 665-683.

Albarracin, D., Johnson, B. T., Fishbein, M., \& Muellerleile, P. A. (2001). Theories of reasoned action and planned behavior as models of condom use: A meta-analysis. Psychological Bulletin, 127(1), 142-161.

Armitage, C. J. (2009). Is there utility in the transtheoretical model? British Journal of Health Psychology, 14, 195-210.

Armitage, C. J., \& Conner, M. (2001). Efficacy of the theory of planned behaviour: A meta-analytic review. British Journal of Social Psychology, 40, 471-499.

Armitage, C. J., \& Talibudeen, L. (2010). Test of a brief theory of planned behaviour-based intervention to promote adolescent safe sex intentions. British Journal of Psychology, 101, $155-172$.

Arnow, B. A., Blasey, C., Manber, R., Constantino, M. J., Markowitz, J. C., Klein, D. N., et al. (2007). Dropouts versus completers among chronically depressed outpatients. Journal of Affective Disorders, 97(1-3), 197-202. 
Barak, A., Hen, L., Boniel-Nissim, M., \& Shapira, N. (2008). A comprehensive review and a metaanalysis of the effectiveness of internet-based psychotherapeutic interventions. Journal of Technology in Human Services, 109-160.

Barrett, M. S., Chua, W.-J., Crits-Christoph, P., Gibbons, M. B., \& Thompson, D. (2008). Early withdrawal from mental health treatment: Implications for psychotherapy practice. Psychotherapy: Theory, Research, Practice, Training, 45(2), 247-267.

Baruch, G., Vrouva, I., \& Fearon, P. (2009). A follow-up study of characteristics of young people that dropout and continue psychotherapy: Service implications for a clinic in the community. Child and Adolescent Mental Health, 14(2), 69-75.

Bauer, S., Percevic, R., Okon, E., Meermann, R., \& Kordy, H. (2003). Use of text messaging in the aftercare of patients with bulimia nervosa. European Eating Disorders Review, 11(3), 279290.

Beck, A. T., Rush, A. J., Shaw, B. F., \& Emery, G. (1979). Cognitive Therapy of Depression. New York, N.Y.: The Guilford Press.

Bender, K. G., \& Koshy, M. K. (1991). Returning for follow up: attendance compliance in an Indian psychiatric clinic. Int J Soc Psychiatry, 37(3), 173-181.

Boschen, M. J., \& Casey, L. M. (2008). The Use of Mobile Telephones as Adjuncts to Cognitive Behavioral Psychotherapy. Professional Psychology-Research and Practice, 39(5), 546-552.

Brezinka, V. (2008). Treasure Hunt - a serious game to support psychotherapeutic treatment of children. Ehealth Beyond the Horizon - Get It There, 136, 71-76.

Bridle, C., Riemsma, R. P., Pattenden, J., Sowden, A. J., Mather, L., Watt, I. S., et al. (2005). Systematic review of the effectiveness of health behavior interventions based on the transtheoretical model. Psychology \& Health, 20(3), 283-301.

Buckley, P. F. (2008). Factors that influence treatment success in schizophrenia. [Article]. Journal of Clinical Psychiatry, 69, 4-10.

Bull, S. S., Gaglio, B., McKay, H. G., \& Glasgow, R. E. (2005). Harnessing the potential of the internet to promote chronic illness self-management: diabetes as an example of how well we are doing. Chronic Illn, 1(2), 143-155. 
Burns, D. D., \& Nolenhoeksema, S. (1991). Coping styles, homework compliance, and the effectiveness of cognitive behavioral-therapy. Journal of Consulting and Clinical Psychology, 59(2), 305-311.

Burns, D. D., \& Spangler, D. L. (2000). Does psychotherapy homework lead to improvements in depression in cognitive-behavioral therapy or does improvement lead to increased homework compliance? Journal of Consulting and Clinical Psychology, 68(1), 46-56.

Buunk, B. P., \& Nauta, A. (2000). Why intraindividual needs are not enough: Human motivation is primarily social. Psychological Inquiry, 11(4), 279-283.

Carlbring, P., \& Andersson, G. (2006). Internet and psychological treatment. How well can they be combined? Computers in Human Behavior, 22(3), 545-553.

Carrion, P. G., Swann, A., Kellertcecil, H., \& Barber, M. (1993). Compliance with clinic attendance by outpatients with schizophrenia. Hospital and Community Psychiatry, 44(8), 764-767.

Carroll, K. M., Ball, S. A., Martino, S., Nich, C., Babuscio, T. A., Nuro, K. F., et al. (2008). Computer-assisted delivery of cognitive-behavioral therapy for addiction: A randomized trial of CBT4CBT. American Journal of Psychiatry, 165(7), 881-888.

Carroll, K. M., Nich, C., \& Ball, S. A. (2005). Practice makes progress? Homework assignments and outcome in treatment of cocaine dependence. Journal of Consulting and Clinical Psychology, 73(4), 749-755.

Carver, C. S., \& Scheier, M. F. (2000). Autonomy and self-regulation. Psychological Inquiry, 11(4), 284-291.

Casey, L. M., \& Halford, W. K. (2010). Couples and the Silicon Chip: Applying Technology to Couple Relationship Services. In K. Hahlweg, M. Grawe \& D. Baucom (Eds.), Enhancing Couples: The Shape of Couple Therapy to Come (pp. 216 - 230). Hogrefe: Gottingen.

Casey, L. M., Oei, T. P. S., \& Newcombe, P. A. (2005). Looking beyond the negatives: A time period analysis of positive cognitions, negative cognitions, and working alliance in cognitivebehavior therapy for panic disorder. Psychotherapy Research, 15(1-2), 55-68. 
Chariatte, V., Berchtold, A., Akre, C., Michaud, P. A., \& Suris, J. C. (2008). Missed appointments in an outpatient clinic for adolescents, an approach to predict the risk of missing. Journal of Adolescent Health, 43(1), 38-45.

Chen, A. (1991). Noncompliance in community psychiatry - a review of clinical interventions. Hospital and Community Psychiatry, 42(3), 282-287.

Chen, K. C., \& Jang, S. J. (2010). Motivation in online learning: Testing a model of selfdetermination theory. Computers in Human Behavior, 26(4), 741-752.

Clarke, B., \& Schoech, D. (1994). A computer-assisted therapeutic game for adolescents: initial development and comments. Computers in Human Services, 11(1-2), 121-140.

Clough, B. A., \& Casey, L. M. (2011). Technological Adjuncts to Enhance Current Psychotherapy Practices: A Review. Clinical Psychology Review, 31(3), 279-292.

Conduit, T., Byrne, S., Court, J., \& Stefanovic, S. (2004). Non-attendance at a university-based psychology clinic: Telephone appointment reminders versus no reminders. Australian Psychologist, 39(1), 68-75.

Conner, M., Kirk, S. F. L., Cade, J. E., \& Barrett, J. H. (2003). Environmental influences: Factors influencing a woman's decision to use dietary supplements. [Article]. Journal of Nutrition, 133(6), 1978S-1982S.

Coyle, D., Matthews, M., Sharry, J., Nisbet, A., \& Doherty, G. (2005). Personal Investigator: A therapeutic 3D game for adolescent psychotherapy. Interactive Technology and Smart Education, 2, 73-88.

Deci, E. L., \& Ryan, R. M. (2000). The "what" and "why" of goal pursuits: Human needs and the selfdetermination of behavior. Psychological Inquiry, 11(4), 227-268.

Deci, E. L., \& Ryan, R. M. (2008). Self-determination theory: A macrotheory of human motivation, development, and health. Canadian Psychology/Psychologie canadienne, 49(3), 182-185.

Detweiler-Bedell, J. B., \& Whisman, M. A. (2005). A lesson in assigning homework: Therapist, client, and task characteristics in cognitive therapy for depression. Professional PsychologyResearch and Practice, 36(2), 219-223. 
Doll, J., \& Ajzen, I. (1992). Accessibility and stability of predictors in the theory of planned behavior. Journal of Personality and Social Psychology, 63(5), 754-765.

Downer, S. R., Meara, J. G., \& Da Costa, A. C. (2005). Use of SMS text messaging to improve outpatient attendance. Medical Journal of Australia, 183(7), 366-368.

Drieschner, K. H., Lammers, S. M. M., \& van der Staak, C. P. F. (2004). Treatment motivation: An attempt for clarification of an ambiguous concept. Clinical Psychology Review, 23(8), 11151137.

Edelman, R. E., \& Chambless, D. L. (1995). Adherence during sessions and homework in cognitivebehavioral group treatment of social phobia. Behaviour Research and Therapy, 33(5), 573577.

El-Mallakh, R. S., James, T., Khan, T., Katz, M., McGovern, B., Nair, S., et al. (2004). Follow-up after inpatient psychiatric hospitalization with partial control of the system responsiveness variable. Psychiatry-Interpersonal and Biological Processes, 67(3), 294-298.

Favelle, G. K. (1994). Therapeutic applications of commercially available computer software. Computers in Human Services|Computers in Human Services, 11(1-2), 151-158.

Festinger, D. S., Lamb, R. J., Marlowe, D. B., \& Kirby, K. C. (2002). From telephone to office Intake attendance as a function of appointment delay. Addictive Behaviors, 27(1), 131-137.

Fishbein, M., \& Ajzen, I. (1975). Belief, attitude, intention, and behavior: An introduction to theory and research. Reading, MA: Addison-Wesley.

Fisher, C. B., \& Oransky, M. (2008). Informed consent to psychotherapy: Protecting the dignity and respecting the autonomy of patients. [Article]. Journal of Clinical Psychology, 64(5), 576588.

France, D. G., \& Dugo, J. M. (1985). Pretherapy orientation as preparation for open psychotherapy groups. Psychotherapy, 22(2), 256-261.

Freeman, A., \& Rosenfield, B. (2002). Modifying therapeutic homework for patients with personality disorders. Journal of Clinical Psychology, 58(5), 513-524. 
Friedman, I. M., \& Litt, I. F. (1987). Adolescents' compliance with therapeutic regimens: Psychological and social aspects and intervention. Journal of Adolescent Health Care, 8(1), $52-67$.

Gardner, J. E. (1991). Can the Mario Bros help? Nintendo games as an adjunct in psychotherapy with children. Psychotherapy, 28(4), 667-670.

Golkaramnay, V., Bauer, S., Haug, S., Wolf, M., \& Kordy, H. (2007). The exploration of the effectiveness of group therapy through an internet chat as aftercare: A controlled naturalistic study. Psychotherapy and Psychosomatics, 76(4), 219-225.

Gonzalez, V. M., Schmitz, J. M., \& DeLaune, K. A. (2006). The role of homework in cognitivebehavioral therapy for cocaine dependence. Journal of Consulting and Clinical Psychology, 74(3), 633-637.

Goss, S., \& Anthony, K. (2009). Developments in the use of technology in counselling and psychotherapy. British Journal of Guidance \& Counselling, 37(3), 223-230.

Griffiths, M. D. (2004). The Therapeutic Value of Video Games. In J. Goldstein \& J. Raessens (Eds.), Handbook of Computer Game Studies (pp. 161-173). Boston, USA: MIT Press.

Halvari, A. E., Halvari, H., Bjornebekk, G., \& Deci, E. L. (2010). Motivation and anxiety for dental treatment: Testing a self-determination theory model of oral self-care behaviour and dental clinic attendance. Motivation and Emotion, 34(1), 15-33.

Harmon, S. C., Lambert, M. J., Smart, D. M., Hawkins, E., Nielsen, S. L., Slade, K., et al. (2007). Enhancing outcome for potential treatment failures: Therapist client feedback and clinical support tools. Psychotherapy Research, 17(4), 379-392.

Haynes, R. B., McDonald, H. P., \& Garg, A. X. (2002). Helping patients follow prescribed treatment Clinical applications. Jama-Journal of the American Medical Association, 288(22), 28802883.

Helbig, S., \& Fehm, L. (2004). Problems with homework in CBT: Rare exception or rather frequent? Behavioural and Cognitive Psychotherapy, 32(3), 291-301.

Hochstadt, N. J., \& Trybula, J. (1980). Reducing missed initial appointments in a community mental health center. J Community Psychol, 8(3), 261-265. 
Horowitz, S. M. (2003). Applying the transtheoretical model to pregnancy and STD prevention: A review of the literature. American Journal of Health Promotion, 17(5), 304-328.

Hoste, R. R., Zaitsoff, S., Hewell, K., \& le Grange, D. (2007). What can dropouts teach us about retention in eating disorder treatment studies? International Journal of Eating Disorders, 40, 668-671.

Hubbard, R. L., Leimberger, J. D., Haynes, L., Patkar, A. A., Holter, J., Liepman, M. R., et al. (2007). Telephone enhancement of long-term engagement (TELE) in continuing care for substance abuse treatment: A NIDA clinical trials network (CTN) study. The American Journal on Addictions, 16(6), 495-502.

Ilgen, M. A., Hu, K. U., Moos, R. H., \& McKellar, J. (2008). Continuing care after inpatient psychiatric treatment for patients with psychiatric and substance use disorders. Psychiatric Services, 59(9), 982-988.

Jackson, K. R., Booth, P. G., Salmon, P., \& McGuire, J. (2009). The effects of telephone prompting on attendance for starting treatment and retention in treatment at a specialist alcohol clinic. British Journal of Clinical Psychology, 48, 437-442.

Jacobson, N. S., \& Truax, P. (1991). Clinical significance: A statistical approach to defining meaningful change in psychotherapy research. Journal of Consulting and Clinical Psychology, 59(1), 12-19.

Kam, J. A., Matsunaga, M., Hecht, M. L., \& Ndiaye, K. (2009). Extending the Theory of Planned Behavior to Predict Alcohol, Tobacco, and Marijuana Use Among Youth of Mexican Heritage. Prevention Science, 10(1), 41-53.

Kazantzis, N., \& Ronan, K. R. (2006). Can between-session (homework) activities be considered a common factor in psychotherapy? Journal of Psychotherapy Integration, 16(2), 115-127.

Kicklighter, B. L. (2001). Effects of pretherapy contacts upon client attendance, therapeutic alliance, session satisfaction and pretherapy anxiety at a university training facility. Dissertation Abstracts International: Section B: The Sciences and Engineering, 62(6-B), 2959.

Kirsch, I., Lynn, S. J., Vigorito, M., \& Miller, R. R. (2004). The role of cognition in classical and operant conditioning. Journal of Clinical Psychology, 60(4), 369-392. 
Klinkenberg, W. D., \& Calsyn, R. J. (1996). Predictors of receipt of aftercare and recidivism among persons with severe mental illness: A review. Psychiatric Services, 47(5), 487-496.

Kluger, M. P., \& Karras, A. (1983). Strategies for reducing missed initial appointments in a community-mental-health-center. Community Mental Health Journal, 19(2), 137-143.

Kobelt, A., \& Schmid-Ott, G. (2010). Results of long-term follow-up study of inpatient psychotherapy followed by systematic outpatient psychotherapeutic aftercare. Psychology, Health \& Medicine, 15(1), 94-104.

Kourany, R. F. C., Garber, J., \& Tornusciolo, G. (1990). Improving first appointment attendance rates in child psychiatry outpatient clinics. Journal of the American Academy of Child and Adolescent Psychiatry, 29(4), 657-660.

Kranzler, H. R., Abu-Hasaballah, K., Tennen, H., Feinn, R., \& Young, K. (2004). Using Daily Interactive Voice Response Technology to Measure Drinking and Related Behaviors in a Pharmacotherapy Study. Alcoholism: Clinical and Experimental Research, 28(7), 1060-1064.

Krause, M. S. (1967). Behavioral indexes of motivation for treatment. Journal of Counseling Psychology, 14(5), 426-\&.

Kuvaas, B. (2009). A test of hypotheses derived from self-determination theory among public sector employees. Employee Relations, 31(1), 39-56.

Lambert, M. J., Hansen, N. B., \& Finch, A. E. (2001). Patient-focused research: Using patient outcome data to enhance treatment effects. Journal of Consulting and Clinical Psychology, 69(2), 159-172.

Lambert, M. J., Harmon, C., Slade, K., Whipple, J. L., \& Hawkins, E. J. (2005). Providing feedback to psychotherapists on their patients' progress: Clinical results and practice suggestions. Journal of Clinical Psychology, 61(2), 165-174.

Landsberger, H. A. (1958). Hawthorne Revisited. Ithaca, NY: Cornell University.

Lash, S. J. (1998). Increasing participation in substance abuse aftercare treatment. American Journal of Drug and Alcohol Abuse, 24(1), 31-36.

Lash, S. J., \& Blosser, S. L. (1999). Increasing adherence to substance abuse aftercare group therapy. Journal of Substance Abuse Treatment, 16(1), 55-60. 
Lefforge, N. L., Donohue, B., \& Strada, M. J. (2007). Improving session attendance in mental health and substance abuse settings: A review of controlled studies. Behavior Therapy, 38(1), 1-22.

Leong, K. C., Chen, W. S., Leong, K. W., Mastura, I., Mimi, O., Sheikh, M. A., et al. (2006). The use of text messaging to improve attendance in primary care: a randomized controlled trial. Family Practice, 23(6), 699-705.

Leung, A. W., \& Heimberg, R. G. (1996). Homework compliance, perceptions of control, and outcome of cognitive-behavioral treatment of social phobia. Behaviour Research and Therapy, 34(5-6), 423-432.

Loeb, K. L., Wilson, G. T., Labouvie, E., Pratt, E. M., Hayaki, J., Walsh, B. T., et al. (2005). Therapeutic alliance and treatment adherence in two interventions for bulimia nervosa: A study of process and outcome. Journal of Consulting and Clinical Psychology, 73(6), 10971106.

Lynch, K. G., Van Horn, D., Drapkin, M., Ivey, M., Coviello, D., \& McKay, J. R. (2010). Moderators of response to telephone continuing care for alcoholism. Am J Health Behav, 34(6), 788-800.

MacNair, R. R., \& Corazzini, J. G. (1994). Client factors influencing group therapy dropout. Psychotherapy: Theory, Research, Practice, Training, 31(2), 352-362.

Madden, T. J., Ellen, P. S., \& Ajzen, I. (1992). A comparison of the theory of planned behavior and the theory of reasoned action. Personality and Social Psychology Bulletin, 18(1), 3-9.

Marini, M., Semenzin, M., Vignaga, F., Gardiolo, M., Drago, A., Caon, F., et al. (2005). Dropout in Institutional Emotional Crisis Counseling and Brief Focused Intervention. Brief Treatment and Crisis Intervention, 5(4), 356.

Martinez, K. K., \& Wong, S. E. (2009). Using Prompts to Increase Attendance at Groups for Survivors of Domestic Violence. Research on Social Work Practice, 19(4), 460-463.

McDonald, H. P., Garg, A. X., \& Haynes, R. (2002). Interventions to enhance patient adherence to medication prescriptions: Scientific review. JAMA: Journal of the American Medical Association, 288(22), 2868-2879. 
McKay, J. R., Lynch, K. G., Shepard, D. S., \& Pettinati, H. M. (2005). The Effectiveness of Telephone-Based Continuing Care for Alcohol and Cocaine Dependence: 24-Month Outcomes. Archives of General Psychiatry, 62(2), 199-207.

McKay, J. R., McLellan, A. T., Alterman, A. I., Cacciola, J. S., Rutherford, M. J., \& O'Brien, C. P. (1998). Predictors of participation in aftercare sessions and self-help groups following completion of intensive outpatient treatment for substance abuse. Journal of Studies on Alcohol, 59(2), 152-162.

Melville, K. M., Casey, L. M., \& Kavanagh, D. J. (2007). Psychological treatment dropout among pathological gamblers. Clinical Psychology Review, 27, 944-958.

Milne, R. G., Horne, M., \& Torsney, B. (2006). SMS reminders in the UK national health service: An evaluation of its impact on "No-Shows" at hospital out-patient clinics. Health Care Management Review, 31(2), 130-136.

Murdoch, J. W., \& Connor-Greene, P. A. (2000). Enhancing therapeutic impact and therapeutic alliance through electronic mail homework assignments. Journal of Psychotherapy Practice and Research, 9(4), 232-237.

Nehl, E. J., Blanchard, C. A., Peng, C. Y. J., Rhodes, R. E., Kupperman, J., Sparling, P. B., et al. (2009). Understanding Nonsmoking in African American and Caucasian College Students: An Application of the Theory of Planned Behavior. Behavioral Medicine, 35(1), $23-29$.

Nguyen, M. N., Potvin, L., \& Otis, J. (1997). Regular exercise in 30- to 60-year-old men: Combining the stages-of-change model and the theory of planned behavior to identify determinants for targeting heart health interventions. Journal of Community Health, 22(4), 233-246.

Nose, M., Barbui, C., Gray, R., \& Tansella, M. (2003). Clinical interventions for treatment nonadherence in psychosis: meta-analysis. British Journal of Psychiatry, 183, 197-206.

Ogrodniczuk, J. S., Joyce, A. S., \& Piper, W. E. (2005). Strategies for Reducing Patient-Initiated Premature Termination of Psychotherapy. Harvard Review of Psychiatry, 13(2), 57-70.

Owen, C., Rutherford, V., Jones, M., Tennant, C., \& Smallman, A. (1997). Noncompliance in psychiatric aftercare. Community Mental Health Journal, 33(1), 25-34. 
Piper, W. E., Debbane, E. G., Garant, J., \& Bienvenu, J. P. (1979). Pretraining for grouppsychotherapy- cognitive-experiential approach. Archives of General Psychiatry, 36(11), 1250-1256.

Prochaska, J. O., \& Diclemente, C. C. (1983). Stages and processes of self-change of smoking Toward an integrative model of change. Journal of Consulting and Clinical Psychology, 51(3), 390-395.

Prochaska, J. O., \& Velicer, W. F. (1997). The transtheoretical model of health behavior change. [Article]. American Journal of Health Promotion, 12(1), 38-48.

Przybylski, A. K., Rigby, C., \& Ryan, R. M. (2010). A motivational model of video game engagement. Review of General Psychology, 14(2), 154-166.

Ramana, R., Paykel, E. S., Melzer, D., Mehta, M. A., \& Surtees, P. G. (2003). Aftercare of depressed inpatients - Service delivery and unmet needs. Social Psychiatry and Psychiatric Epidemiology, 38(3), 109-115.

Riemsma, R. P., Pattenden, J., Bridle, C., Sowden, A. J., Mather, L., Watt, I. S., et al. (2002). A systematic review of the effectiveness of interventions based on a stages-of-change approach to promote individual behaviour change. Health Technol Assess, 6(24), 1-231.

Robinson, S., Perkins, S., Bauer, S., Hammond, N., Treasure, J., \& Schmidt, U. (2006). Aftercare intervention through text messaging in the treatment of bulimia nervosa - Feasibility pilot. International Journal of Eating Disorders, 39(8), 633-638.

Rothbaum, B. (2004). Technology and manual-based therapies. Clinical Psychology-Science and Practice, 11(3), 339-341.

Ryan, R. M., \& Deci, E. L. (2000). Self-determination theory and the facilitation of intrinsic motivation, social development, and well-being. American Psychologist, 55(1), 68-78.

Ryan, R. M., \& Deci, E. L. (2008). A self-determination theory approach to psychotherapy: The motivational basis for effective change. Canadian Psychology/Psychologie canadienne, 49(3), 186-193. 
Sannibale, C., Hurkett, P., Van den Bossche, E., O'Connor, D., Zador, D., Capus, C., et al. (2003). Aftercare attendance and post-treatment functioning of severely substance dependent residential treatment clients. Drug and Alcohol Review, 22(2), 181-190.

Scheel, M. J., Hanson, W. E., \& Razzhavaikina, T. I. (2004). The Process of Recommending Homework in Psychotherapy: A Review of Therapist Delivery Methods, Client Acceptability, and Factors That Affect Compliance. Psychotherapy: Theory, Research, Practice, Training, 41(1), 38-55.

Shivack, I. M., \& Sullivan, C. W. (1989). Use of telephone prompts at an inner-city outpatient-clinic. Hospital and Community Psychiatry, 40(8), 851-853.

Shoffner, J., Staudt, M., Marcus, S., \& Kapp, S. (2007). Using telephone reminders to increase attendance at psychiatric appointments: Findings of a pilot study in rural Appalachia. Psychiatric Services, 58(6), 872-875.

Stasiewicz, P. R., \& Stalker, R. (1999). A comparison of three "interventions" on pretreatment dropout rates in an outpatient substance abuse clinic. Addictive Behaviors, 24(4), 579-582.

Swenson, T. R., \& Pekarik, G. (1988). Interventions for reducing missed initial appointments at a community mental-health center. Community Mental Health Journal, 24(3), 205-218.

Tanke, E. D., \& Leirer, V. O. (1994). Automated telephone reminders in tuberculosis care. Medical Care, 32(4), 380-389.

Thogersen-Ntoumani, C., Ntoumanis, N., \& Nikitaras, N. (2010). Unhealthy weight control behaviours in adolescent girls: A process model based on self-determination theory. Psychology \& Health, 25(5), 535-550.

Tickner, S., Leman, P. J., \& Woodcock, A. (2010). The Immunisation Beliefs and Intentions Measure (IBIM): Predicting parents' intentions to immunise preschool children. Vaccine, 28(19), 33503362.

Titov, N., Andrews, G., Robinson, E., Schwencke, G., Johnston, L., Solley, K., et al. (2009). Clinician-assisted Internet-based treatment is effective for generalized anxiety disorder: randomized controlled trial. [Article]. Australian and New Zealand Journal of Psychiatry, 43(10), 905-912. 
Turner, A., \& Vernon, J. C. (1976). Prompts to increase attendance in a community mental-health center. Journal of Applied Behavior Analysis, 9(2), 141-145.

Vermeersch, D. A., Lambert, M. J., \& Burlingame, G. M. (2000). Outcome questionnaire: item sensitivity to change. Journal of Personality Assessment, 74(2), 242-261.

Vielva, I., \& Iraurgi, I. (2001). Cognitive and behavioural factors as predictors of abstinence following treatment for alcohol dependence. Addiction, 96(2), 297-303.

Watt, B. D., Hoyland, M., Best, D., \& Dadds, M. R. (2007). Treatment participation among children with conduct problems and the role of telephone reminders. Journal of Child and Family Studies, 16(4), 522-530.

West, R. (2005a). Time for a change: putting the Transtheoretical (Stages of Change) Model to rest. Addiction, 100(8), 1036-1039.

West, R. (2005b). What does it take for a theory to be abandoned? The transtheoretical model of behaviour change as a test case. Addiction, 100(8), 1048-1050.

Westra, H. A., Dozois, D. J. A., \& Marcus, M. (2007). Expectancy, homework compliance, and initial change in cognitive-behavioral therapy for anxiety. Journal of Consulting and Clinical Psychology, 75(3), 363-373.

White, K. M., Terry, D. J., Troup, C., Rempel, L. A., \& Norman, P. (2010). Predicting the consumption of foods low in saturated fats among people diagnosed with Type 2 diabetes and cardiovascular disease. The role of planning in the theory of planned behaviour. Appetite, 55(2), 348-354.

Williams, G. C., McGregor, H. A., Sharp, D., Levesque, C., Kouides, R. W., Ryan, R. M., et al. (2006). Testing a self-determination theory intervention for motivating tobacco cessation: Supporting autonomy and competence in a clinical trial. Health Psychology, 25(1), 91-101.

Williams, G. C., McGregor, H. A., Zeldman, A., Freedman, Z. R., \& Deci, E. L. (2004). Testing a Self-Determination Theory Process Model for Promoting Glycemic Control Through Diabetes Self-Management. Health Psychology, 23(1), 58-66. 
Winston, A., Pardes, H., Papernik, D. S., \& Breslin, L. (1977). Aftercare of psychiatric-patients and its relation to rehospitalization. [Article]. Hospital and Community Psychiatry, 28(2), 118121.

Zanjani, F., Miller, B., Turiano, N., Ross, J., \& Oslin, D. (2008). Effectiveness of telephone-based referral care management, a brief intervention to improve psychiatric treatment engagement. Psychiatric Services, 59(7), 776-781. 
Table 1

Appointment Reminders Using Technological Devices

\begin{tabular}{ll}
\hline Study & Sample \\
\hline (Conduit et al., 2004) & $\begin{array}{l}N=512 \text { appointments at an } \\
\text { Australian university } \\
\text { psychology clinic. }\end{array}$ \\
$\begin{array}{ll}\text { (Hochstadt \& Trybula, } \\
\text { 1980) }\end{array}$ & $\begin{array}{l}N=88 \text { individuals seeking } \\
\text { help at an outpatient mental } \\
\text { health clinic. }\end{array}$
\end{tabular}

(Jackson, Booth,

Salmon, \& McGuire,

2009)

(Kicklighter, 2001)

$N=172$ clients attending a specialist alcohol treatment clinic as outpatients.

$N=259$ clients attending a university psychology clinic.

(Kluger \& Karras, 1983) $N=141$ individuals seeking help at an outpatient mental health clinic.

(Kourany et al., 1990) $\quad N=111$ outpatients at a university child psychiatry clinic.

(Lash \& Blosser, 1999) $\quad N=41$ substance dependent individuals completing inpatient or extensive outpatient treatment.

(Martinez \& Wong, 2009)

$N=15$ female victims of domestic violence participating in group therapy as part of a residential programme.

Method

Reminder calls made in alternating weeks over a 20 week period. Calls were made one week prior to scheduled appointments.

Participants assigned sequentially to treatment conditions; control, telephone prompt one day prior, telephone prompt three days prior, or letter prompt three days prior to appointment.

A multiple baselines approach used six alternating four week testing phases. Telephone calls were made to clients as reminders.

Participants randomly assigned to control, telephone, or letter reminder groups.

Participants randomly assigned to conditions; control, orientation letter only, orientation letter and reminder phone call, or reminder phone call only. Calls made within 24 hours of appointment. Participants randomly assigned to control, telephone reminder, orientation letter, or telephone reminder and orientation letter groups.

Participants randomly assigned to control or experimental groups. Experimental group received attendance feedback and prompts related to aftercare group therapy.

Multiple baseline design was utilized. During experimental phases written and telephone prompts were delivered to participants.
Results

Reminders significantly reduced non attendance compared to baseline, but only for first appointments. Females more sensitive to reminders than males.

Temporal proximity of reminder to appointment was the most important factor. The one day prior group displayed significantly reduced initial appointment no-shows (9\%) than the control group (55\%), $\left(\Phi_{c}=.488\right)$.

Reminders improved initial $\left(\Phi_{c}=.250\right)$ and subsequent $\left(\Phi_{c}=.172\right)$ appointment attendance.

No significant differences in first session attendance, or in client anxiety or satisfaction. First appointment attendance significantly higher in the combined orientation and phone prompt group than in the control group $\left(\Phi_{C}=.371\right)$. No other differences between groups.

No differences found in initial appointment attendance rates between intervention groups, although all three significantly improved attendance compared to the control $\left(\Phi_{c}=.178\right)$.

Participants in the prompt and feedback condition more likely to begin $\left(\Phi_{c}=.425\right)$ and maintain an aftercare programme than those in the control condition. Also less likely to be readmitted to hospital.

Prompts more than doubled attendance during intervention phases. No statistical analyses conducted. Individual treatment effects of the letter and phone prompts were also not analysed. 
(Shivack \& Sullivan, 1989)

(Shoffner et al., 2007)

(Stasiewicz \& Stalker, 1999)

(Turner \& Vernon, 1976)

(Watt et al., 2007)

(Zanjani, Miller, Turiano, Ross, \& Oslin, 2008)
$N=660$ individuals referred

to a community mental health centre.

$N=451$ appointments scheduled over a nine week period at a rural mental health centre. Two pilot studies.

$N=128$ individuals seeking outpatient treatment at a substance abuse clinic.

$N=1355$ individuals seeking treatment at a community mental health clinic $N=262$ consecutive referrals to two child and youth mental health clinics.

$N=113$ psychiatric outpatients
Design included two baseline and one

intervention phases. Telephone reminders made to patients one day prior to scheduled appointments. No control group.

Experimental conditions were randomly assigned to each week of the nine week testing period.

Conditions were no reminder calls, therapist made calls, and staff made calls.

Participants randomly assigned to one of four groups. First group had appointments scheduled within 48 hours of contact, no reminders given. Remaining three groups had appointments scheduled more than 48 hours after initial contact. Given either a telephone, mail or no reminder.

Multiple baseline design utilized. During intervention phases telephone prompts delivered to clients one to three days before appointments. Participants randomly assigned. Intervention group received telephone reminder calls prior to scheduled appointment. Control group received no appointment reminders.

Randomly assigned to usual care (appointment, mailed reminder and telephone reminder) or intervention (usual care plus two motivational telephone sessions).
Prompts increased first appointment attendance, particularly when direct rather than indirect contact was made with the patient $\left(\Phi_{C}=.201\right)$. No statistical analyses.

Reminders with direct therapist contact significantly increased client attendance,

particularly for intake sessions. No effect for other reminder conditions.

Intake attendance significantly higher for appointments scheduled within 48 hours of initial contact. Neither reminder condition significantly increased attendance when compared to the no reminder condition $(d=.025)$. No groups differed in attendance for subsequent therapy sessions. Phone prompts reduced no-shows from 32\% to $11 \%$. No statistical analyses.

Reminders effective at increasing attendance, but only for adolescents with conduct disorder. This

group had a lower initial attendance rate.

Intervention increased attendance rates to those of adolescents without conduct disorder.

Greater number of participants in the intervention group attended at least one appointment, also attended a greater number overall than the control group $(d=.33)$. 
Table 2

Technology to Increase Client Engagement

\begin{tabular}{|c|c|c|c|}
\hline Study & Sample & Method & Results \\
\hline (Brezinka, 2008) & $\begin{array}{l}\text { Children and adolescents } \\
\text { presenting for outpatient } \\
\text { psychological treatment }\end{array}$ & $\begin{array}{l}\text { Computer game incorporated cognitive behaviour } \\
\text { modification training with electronic homework } \\
\text { assignments. }\end{array}$ & $\begin{array}{l}\text { Children and therapists responded positively to the } \\
\text { programme. Children enjoyed playing the game, } \\
\text { and therapists found it useful as positive } \\
\text { reinforcement. No compliance data was collected. }\end{array}$ \\
\hline (Carroll et al., 2008) & $\begin{array}{l}N=77 \text { individuals seeking } \\
\text { treatment for substance } \\
\text { dependence }\end{array}$ & $\begin{array}{l}\text { Participants randomly assigned to CBT treatment } \\
\text { or CBT combined with additional biweekly CBT } \\
\text { skills training delivered by computer. }\end{array}$ & $\begin{array}{l}\text { Participants in CBT computer group submitted } \\
\text { fewer urine samples positive for drugs ( }(d=0.59) \text {, } \\
\text { and had longer continuous periods of abstinence ( } d \\
=0.44) \text {. Increased engagement and homework } \\
\text { adherence was associated with better outcomes. }\end{array}$ \\
\hline $\begin{array}{l}\text { (Clarke \& Schoech, } \\
\text { 1994) }\end{array}$ & $\begin{array}{l}4 \mathrm{X} N=1 \text { adolescents with } \\
\text { low impulse control, }(4 \\
\text { adolescent case studies) }\end{array}$ & $\begin{array}{l}\text { Computer game based on cognitive treatment for } \\
\text { low impulse control. Game was used during } \\
\text { therapy sessions to increase engagement. }\end{array}$ & $\begin{array}{l}\text { Attendance in therapy increased. Clients became } \\
\text { more cooperative and enthusiastic. Impulse control } \\
\text { behaviours improved. No statistical analyses. }\end{array}$ \\
\hline (Coyle et al., 2005) & $\begin{array}{l}4 \mathrm{X} N=1 \text { adolescent } \\
\text { outpatients, (4 case studies) }\end{array}$ & $\begin{array}{l}\text { Computer game was developed with elements of } \\
\text { Solution Focused Therapy. The game was used in } \\
\text { therapy sessions to increase engagement. }\end{array}$ & $\begin{array}{l}\text { Therapists rated the game as being easy to integrate } \\
\text { into therapy. Also reported that the use of the game } \\
\text { increased client engagement during sessions. } \\
\text { Clients reported the game was fun and enjoyable. } \\
\text { No analyses were conducted. }\end{array}$ \\
\hline (Gardner, 1991) & $\begin{array}{l}4 \mathrm{X} N=1 \text { adolescent } \\
\text { outpatients, ( } 4 \text { case studies) }\end{array}$ & $\begin{array}{l}\text { Nintendo games used during therapy to increase } \\
\text { engagement and observe child behaviours. }\end{array}$ & $\begin{array}{l}\text { Social anxiety decreased and self efficacy } \\
\text { increased. Improvements in impulse control. No } \\
\text { statistical analyses. }\end{array}$ \\
\hline $\begin{array}{l}\text { (Murdoch \& Connor- } \\
\text { Greene, 2000) }\end{array}$ & $2 \mathrm{X} N=1$, (2 case studies) & Homework assignments completed by email. & $\begin{array}{l}\text { Emails facilitated increased self disclosure and } \\
\text { engagement during therapy sessions. Homework } \\
\text { adherence increased by therapists sending reminder } \\
\text { emails when homework had not been received. No } \\
\text { statistical analyses performed. }\end{array}$ \\
\hline
\end{tabular}


Table 3

Technology to Increase Adherence to Aftercare

\begin{tabular}{|c|c|c|c|}
\hline Study & Sample & Method & Results \\
\hline (Bauer et al., 2003) & $N=30$ bulimic patients & $\begin{array}{l}\text { Used SMS communication to monitor and provide } \\
\text { support to patients in an aftercare programme. }\end{array}$ & $\begin{array}{l}\text { Low attrition and high engagement with programme. } \\
\text { Most participants valued the extra support and would } \\
\text { recommend the programme. }\end{array}$ \\
\hline $\begin{array}{l}\text { (Golkaramnay et al., } \\
\text { 2007) }\end{array}$ & $\begin{array}{l}N=228 \text { recently discharged } \\
\text { from inpatient treatment for a } \\
\text { variety of psychological } \\
\text { complaints }\end{array}$ & $\begin{array}{l}\text { Participants non-randomly assigned to control or } \\
\text { experimental conditions. Experimental conditions } \\
\text { consisted of weekly } 90 \text { minute online group chat } \\
\text { sessions over } 12-15 \text { weeks. }\end{array}$ & $\begin{array}{l}\text { At one year follow up participants in the treatment } \\
\text { group were at lower risk for negative outcomes than } \\
\text { the controls, and displayed significantly reduced } \\
\text { psychological stress as measured by the OQ- } 45 \text { ( } d= \\
.32 \text { ). Also low dropout rate and attendance. }\end{array}$ \\
\hline (Hubbard et al., 2007) & $\begin{array}{l}N=339 \text { patients completing } \\
\text { inpatient and residential } \\
\text { substance abuse programmes }\end{array}$ & $\begin{array}{l}\text { Participants randomized to treatment as usual or } \\
\text { aftercare with added phone reminders and } \\
\text { counselling. }\end{array}$ & $\begin{array}{l}\text { Participants receiving calls attended more aftercare } \\
\text { sessions (48\%) than those not receiving calls (37\%). } \\
\text { Difference not statistically significant. }\end{array}$ \\
\hline (Lynch et al., 2010) & $\begin{array}{l}N=252 \text { receiving intensive } \\
\text { outpatient treatment for } \\
\text { alcohol dependence }\end{array}$ & $\begin{array}{l}\text { Participants randomly assigned to telephone } \\
\text { monitoring, telephone monitoring with } \\
\text { counselling, or treatment as usual conditions. }\end{array}$ & $\begin{array}{l}\text { Combined outpatient programme with telephone } \\
\text { monitoring and counselling produced significantly } \\
\text { better alcohol use outcomes than did the outpatient } \\
\text { programme alone. Monitoring without counselling } \\
\text { did not enhance the programme. }\end{array}$ \\
\hline $\begin{array}{l}\text { (Robinson et al., } \\
\text { 2006) }\end{array}$ & $N=21 \mathrm{BN}$ patients & $\begin{array}{l}\text { Used SMS communication to monitor and provide } \\
\text { support to patients as an aftercare programme. }\end{array}$ & $\begin{array}{l}\text { Low usage and high attrition. Only moderately } \\
\text { accepted by participants. No significant changes pre } \\
\text { to post treatment in fear of becoming fat }(d=0) \text {, } \\
\text { perception of body shape }(d=-.111) \text {, or perception of } \\
\text { attractiveness }(d=-.0285) \text {. Greater binge episodes } \\
\text { were reported post intervention than pre intervention } \\
(d=-.200)\end{array}$ \\
\hline
\end{tabular}

